\title{
BPDE-induced genotoxicity: relationship between DNA adducts, mutagenicity in the in vitro PIG-A assay, and the transcriptional response to DNA damage in TK6 cells
}

\author{
Ann Liza Piberger ${ }^{1}$ Christopher T. Krüger ${ }^{1} \cdot$ Bettina M. Strauch $^{1}$. \\ Beatrice Schneider ${ }^{1} \cdot$ Andrea Hartwig $^{1}$
}

Received: 2 February 2017 / Accepted: 31 May 2017 / Published online: 7 June 2017

(c) The Author(s) 2017. This article is an open access publication

\begin{abstract}
Benzo $[a]$ pyrene is a known human carcinogen. As underlying mechanism, the induction of stable DNA adducts and mutations have been repeatedly demonstrated. Also, the activation of cellular stress response on the transcriptional level has been described. Nevertheless, the interrelationship between these different events is less well understood, especially at low, for human exposure relevant concentrations. Within the present study, we applied the reactive metabolite benzo[a]pyrene diolepoxide (BPDE) in the nanomolar, non-cytotoxic concentration range in human TK6 cells and quantified the induction and repair of stable DNA adducts at the $N^{2}$-position of guanine by HPLC with fluorescence detection. Significant levels of DNA lesions were detected even at the lowest concentration of $10 \mathrm{nM}$ BPDE, with a linear increase up to $50 \mathrm{nM}$. Relative repair was similar at all damage levels, reaching about $30 \%$ after $8 \mathrm{~h}$ and $60 \%$ after $24 \mathrm{~h}$. Mutation frequencies were quantified as GPI-deficient cells by the recently established in vitro PIG-A mutagenicity assay. Again, a linear dose-response-relationship in the before-mentioned concentration range was observed, also when plotting the number of GPI-deficient cells against the number of DNA adducts. Furthermore, we explored the time- and concentration-dependent DNA damage response
\end{abstract}

Ann Liza Piberger, Christopher T. Krüger and Bettina M. Strauch contributed equally to this work.

Electronic supplementary material The online version of this article (doi:10.1007/s00204-017-2003-0) contains supplementary material, which is available to authorized users.

Andrea Hartwig

andrea.hartwig@kit.edu

1 Food Chemistry and Toxicology, Institute of Applied Bioscience, Karlsruhe Institute of Technology (KIT), Adenauerring 20a, 76131 Karlsruhe, Germany on the transcriptional level via a high-throughput RT-qPCR technique by quantifying the impact of BPDE on the transcription of 95 genes comprising DNA damage response, DNA repair factors, oxidative stress response, cell cycle arrest, cell proliferation, and apoptosis. As expected, BPDE activated DNA damage signaling, p53 and AP-1 dependent signaling, oxidative stress response, and apoptosis. However, in contrast to DNA adducts and mutations, the onset of the transcriptional DNA damage response was restricted to higher concentrations, indicating that its respective activations require a certain level of DNA lesions. Altogether, the results indicate that in case of BPDE, DNA lesions and mutations were correlated at all concentrations, suggesting that repair is not complete even at low levels of DNA damage. Considering the ongoing discussion on potential thresholds also for genotoxic carcinogens, the results are of major relevance, both with respect to basic research as well as to risk assessment of chemical carcinogens.

Keywords BPDE - DNA adducts - DNA repair . Mutations $\cdot$ Gene expression profiling $\cdot$ High throughput RT-qPCR

\section{Introduction}

In spite of manifold precautions to reduce exposure towards hazardous chemicals, there are still many carcinogens present in the environment, at workplaces, and in food. They comprise combustion products, carcinogenic metal compounds, carcinogenic organic chemicals, natural bioactive food ingredients as well as carcinogens generated during storage, production, and preparation of food, such as mycotoxins, acrylamide, nitrosamines, and polycyclic aromatic hydrocarbons. Even though exposure levels have dropped 
considerably during the last decades, this raises the question whether or not there is a carcinogenic risk under realistic exposure conditions. Especially directly genotoxic, i.e., DNA-reactive agents or their DNA-reactive metabolites, are generally assumed to represent risk factors at any concentration, following a linear dose-response also in the low concentration range, implying that even one or a few DNA lesions may result in mutations, and thus, may increase tumor risk. This assumption has repeatedly been challenged during the last years, due to observations that, for example, in case of alkylating compounds such as EMS DNA lesions are linear also in the low dose range, while increases in mutation frequencies follow a non-linear doseresponse relationship (Doak et al. 2007; Gocke and Müller 2009; Jenkins et al. 2010; Pottenger et al. 2009; for recent review see Klapacz et al. 2016). This raised the question whether this may apply for all genotoxic substances, due to, for example, complete repair, as well as other DNA damage response systems in cases of low levels of DNA damage, which are overwhelmed in case of higher levels of DNA adducts (Greim and Albertini 2014; Klapacz et al. 2016). Clearly, with respect to a potential impairment of genomic stability, a distinction has to be made between the occurrence of DNA adducts, which may be repaired, and there conversion into mutations, i.e., irreversible alteration of the genetic information. Nevertheless, repair efficiencies in the low dose range may be different in case of DNA lesions generated also endogenously, such as DNA alkylation damage to DNA bases, and lesions induced exclusively or predominantly by environmental mutagens. While cells may be very well adapted to remove oxidatively induced DNA lesions and most types of DNA base damage induced by alkylating agents via base excision repair (BER), many classes of environmental mutagens such as polycyclic aromatic hydrocarbons (PAHs) induce DNA lesions which provoke DNA helix distortions repaired by nucleotide excision repair (NER). As compared to BER, the latter repair pathway is usually slower and not evenly efficient throughout the genome (Fousteri and Mullenders 2008).

Within the present study we addressed the question on dose-response relationships in the low dose range for benzo $[a]$ pyrene $(\mathrm{BaP})$-induced DNA adducts, their repair, the transcriptional DNA damage response, and the induction of mutations in the same cell line, namely TK6 cells. $\mathrm{BaP}$ belongs to the group of PAHs formed during incomplete combustion or pyrolysis of organic material. Exposure to $\mathrm{BaP}$ provokes manifold adverse effects, including carcinogenicity, immunosuppression, teratogenicity, as well as hormonal effects (Verma et al. 2012). The carcinogenic activity of $\mathrm{BaP}$ is attributed to the formation of DNA adducts, resulting from electrophilic attack predominantly at guanine residues by metabolically activated intermediates formed from the parent hydrocarbon. Routes of metabolic activation include the formation of radical cations via $\mathrm{P} 450$ and/or peroxidases and the formation of $o$-quinones via dihydrodiol dehydrogenases. For carcinogenicity, the probably most relevant metabolic pathway is connected to the action of cytochromes P450 1A1 and 1B1 and epoxide hydrolase, yielding syn- and anti-BaP-7,8diol 9,10-epoxides (BPDE), which mainly form adducts at the $N^{2}$ position of guanine. These lesions are substrates of nucleotide excision repair (NER) (Camenisch and Naegeli 2009; Hess et al. 1997). When DNA is replicated prior to their removal, these adducts can lead to mutations and cancer (Melendez-Colon et al. 1999). To exclude cellular detoxification of $\mathrm{BaP}$ preceding the induction of DNA lesions, within the present study cells were treated with its DNA reactive metabolite, (+)-anti-benzo $[a]$ pyrene 7,8-diol-9,10-epoxide [(+)-anti-BPDE]. Mutations were quantified via the in vitro PIG-A mutagenicity test, which has been recently established for TK6 cells (Krüger et al. 2015). Therefore, to ensure comparable conditions, this cell line was applied for all other endpoints as well. For quantification of (+)-anti-BPDE-induced DNA adducts a highly sensitive HPLC-based assay coupled with fluorescence detection was used, enabling the detection of the respective tetrol I-1 in the very low dose range (Schwerdtle et al. 2002). Finally, we applied a high-throughput RT-qPCR approach to quantitatively elucidate the onset of the transcriptional DNA damage response at the same conditions (Fischer et al. 2016). Our results demonstrate a linear correlation between the amount of DNA adducts and mutations even in the very low concentration range, indicating no threshold-like effect for the conversion of DNA adducts into mutations. Furthermore, the transcriptional DNA damage response was restricted to higher concentrations, at which mutations were already evident.

\section{Materials and methods}

\section{Materials}

RPMI-1640 medium, trypsin, dimethyl sulfoxide (DMSO), and penicillin-streptomycin solutions were purchased from Sigma-Aldrich (Steinheim, Germany) and fetal bovine serum (FBS) from Invitrogen $\mathrm{GmbH}$ (Darmstadt, Germany). Cell culture dishes were from Sarstedt (Nuembrecht, Germany). (+)-anti-benzo[a]pyrene-7,8-diol 9,10-epoxide $((+)$-anti-BPDE) was synthesized by Dr. A. Seidel, Biochemisches Institut für Umweltcarcinogene Grimmer (Grosshansdorf, Germany). Mouse anti-human CD55-PE (clone JS11), mouse anti-human CD59-PE (clone p282), mouse anti-human CD19-APC (clone HIB 19), mouse anti-human CD59 (clone p282), goat anti-mouse IgG (polyclonal), and 7-aminoactinomycin D solution 
(7-AAD, CAS Nr. 7240-37-1) were purchased from Biolegend (London, United Kingdom). Actinomycin D (AD, CAS Nr. 50-76-0) and cycloheximide (CAS Nr. 66-81-9, purity $\geq 96 \%$ ) were obtained from Carl Roth (Karlsruhe, Germany). Proaerolysin (CAS Nr. 110616-75-6) was provided by Dr. Peter Howard (University of Saskatchewan, Canada). Cellstar cell culture dishes (for mutant cleansing), $35 \times 10 \mathrm{~mm}$, were purchased from Greiner bio-one (Frickenhausen, Germany). All PCR consumables including PCR tubes and strips were obtained from Sarstedt (Nuembrecht, Germany). The primer pairs were synthesized by Eurofins (Ebersberg, Germany) or Fluidigm (San Francisco, USA). DNA suspension buffer, PCR certified water, and TE buffer were obtained from Teknova (Hollister, USA). 2X Assay Loading Reagent and 20X DNA Binding Dye Sample Loading Reagent were purchased from Fluidigm (San Francisco, USA). Bio-Rad (Munich, Germany) provided the $2 \mathrm{X}$ SsoFast ${ }^{\mathrm{TM}}$ EvaGreen ${ }^{\circledR}$ Supermix with Low ROX. The $2 \mathrm{X}$ TaqMan ${ }^{\circledR}$ PreAmp Master Mix was obtained from Applied Biosystems (Darmstadt, Germany) and the exonuclease I from New England Biolabs (Frankfurt am Main, Germany). Consumables for the HPLC-based quantification of BPDE-DNA adducts were obtained from Chromatographie Zubehör Trott (Kriftel, Germany). All other chemicals were purchased from Carl Roth (Karlsruhe, Germany).

\section{Cell line, culture conditions and treatment with (+)-anti-BPDE}

Human B-lymphoblastoid TK6 cells were purchased from CLS Cell Lines Service (Eppelheim, Germany). Cells were grown in RPMI-1640 supplemented with $10 \%$ heat-inactivated FBS, $0.3 \mathrm{~g} / \mathrm{L}$ L-glutamine and $2 \mathrm{~g} / \mathrm{L}$ sodium bicarbonate. Cells were grown at $37{ }^{\circ} \mathrm{C}$ and $5 \% \mathrm{CO}_{2}$ in a humidified incubator and were maintained between $0.08 \times 10^{6}$ and $1.00 \times 10^{6}$ cells $/ \mathrm{mL}$. Shortly before the experiment, cells were cleaned from pre-existing mutants as described previously (Krüger et al. 2014). For storage, freshly GPI(-) cleansed TK6 cells were frozen with $3-5 \times 10^{6}$ cells per aliquot in $1 \mathrm{~mL}$ FBS with $10 \%$ DMSO (v/v).

\section{Cytotoxicity}

Cytotoxicity was determined by loss of colony forming ability. TK6 cells were incubated with (+)-anti-BPDE for $1 \mathrm{~h}$, washed with PBS, resuspended in RPMI-1640/FBS, counted, and reseeded in triplicate in 96 well plates with a density of 1.6 cells per well in a total volume of $100 \mu \mathrm{L}$ RPMI-1640/FBS per well. After 8 days the number of wells with cell growth was counted and cytotoxicity was calculated as $\%$ of control.

\section{Quantification of (+)-anti-BPDE-induced DNA adducts}

The adducts were quantified upon acidic release as tetrol I-1 using a HPLC/fluorescence assay described previously (Schwerdtle et al. 2002). Briefly, TK6 cells were incubated with increasing concentrations of $(+)$-anti-BPDE for $1 \mathrm{~h}$. After post-incubation times of 0,8 , or $24 \mathrm{~h}$ aliquots of each $6.5 \times 10^{6}$ cells of the treated suspension cultures were collected as pellet in Tris-buffered saline $(0.0027 \mathrm{M}$ $\mathrm{KCl}, 0.0513 \mathrm{M} \mathrm{NaCl}, 0.025 \mathrm{M}$ Tris-base, pH 7.4)/FBS (10\%), and washed once with Tris-buffered saline (TBS). After DNA isolation with phenol/chloroform/isoamyl alcohol (25:24:1), the DNA was washed three times with $70 \%$ EtOH (Rotisol) and quantified (TECAN NanoQuant). The acidic hydrolysed DNA adducts were quantified as tetrol I- 1 by HPLC, equipped with a Dionex UltiMate 3000 pump and a Gynkotek RF 2000 fluorescence detector.

\section{Pig-A mutation assay}

Cell treatment, sample preparation, and analyses of the GPI(-) frequency were performed as described previously (Krüger et al. 2015). After treatment with BPDE for $1 \mathrm{~h}$, TK6 cells were washed and $2 \times 10^{6}$ cells per treatment were antibody-stained in a total volume of $175 \mu \mathrm{L}$ staining buffer [PBS with $1 \%$ BSA (w/v) and $0.1 \%$ sodium azide $(\mathrm{w} / \mathrm{v})]$. The cells were incubated with previously pooled mouse anti-human CD19-APC, mouse anti-human CD55$\mathrm{PE}$, and mouse anti-human CD59-PE for $30 \mathrm{~min}$ on ice with an additional centrifugation and resuspension step after $15 \mathrm{~min}$. After antibody treatment, cells were washed twice by adding $1 \mathrm{~mL}$ staining buffer and gentle vortexing. Subsequently, cells were incubated with 7-AAD in $500 \mu \mathrm{L}$ staining buffer for $10 \mathrm{~min}$ to exclude dead cells from analysis. Samples were then centrifuged, the supernatant was discarded and cells were fixed in $200 \mu \mathrm{L}$ fixation buffer [PBS with $1 \%$ formaldehyde $(\mathrm{v} / \mathrm{v})$ and $2.5 \mu \mathrm{g} / \mathrm{mL}$ $\mathrm{AD}$. All steps prior to the flow cytometric analysis were performed on ice under exclusion of light. Centrifugation was performed at $250 \times g$ for $5 \mathrm{~min}$ at $4{ }^{\circ} \mathrm{C}$. Flow cytometric analyses were conducted applying a LSR Fortessa from Becton-Dickinson. Excitation and emission detection of the respective fluorescence dyes were as follows: PE (488-575/26 nm), 7-AAD (488-695/40 nm) and APC (640-670/14 nm). Samples were analyzed with $\sim 8.000$ events/s. For one determination of the GPI(-) frequency, $10^{6} \mathrm{GPI}(+)$ cells were collected. To exclude uninformative results of mutagenicity testing due to impaired cell growth after treatment, the relative increase in cell count (RICC) was assessed (Krüger et al. 2015). Directly after the respective treatment, cells were washed with PBS and seeded in triplicate in 24-well plates at a density of $0.1 \times 10^{6}$ cells/ $\mathrm{mL}$ in a total volume of $500 \mu \mathrm{L}$ RPMI-1640/FBS per well. 
After 48-h cell growth, cell numbers were determined and RICC was calculated as described previously:

$\operatorname{RICC}(\%$ of control $)=\left[\left(\right.\right.$ Cell number* $\left.{ }_{\text {treated }}-0.1 \times 10^{6}\right) /$ $\left(\right.$ Cell number* $\left.\left.{ }_{\text {control }}-0.1 \times 10^{6}\right)\right] \times 100,(*$ Cell number in cells $/ \mathrm{mL}$ ).

\section{Gene expression analyses}

Gene expression analyses via high-throughput RT-qPCR analyses with Fluidigm dynamic arrays on the BioMark ${ }^{\mathrm{TM}}$ System were performed as described previously (Fischer et al. 2016). Briefly, $10 \times 10^{6}$ logarithmically growing TK6 cells were treated with BPDE in RPMI containing $10 \%$ FCS. After incubation, cells were washed with icecold PBS and collected by centrifugation. Total RNA was isolated with MN NucleoSpin ${ }^{\circledR}$ RNA Plus KIT (Macherey-Nagel) according to the manufacturer's instructions and quantified. $1 \mu \mathrm{g}$ of total RNA was reverse transcribed in duplicate per sample into first-strand complementary DNA (cDNA) using qScript ${ }^{\mathrm{TM}}$ cDNA Synthesis Kit (Quanta) according to the manufacturer's instructions. Before qPCR, specific target amplification (STA) and exonuclease I (Escherichia coli) treatments were performed. A total of $5 \mu \mathrm{L}$ STA mix was prepared containing $2.5 \mu \mathrm{L}$ of 2X TaqMan ${ }^{\circledR}$ PreAmp Master Mix, $0.5 \mu \mathrm{L}$ of the $500 \mathrm{nM}$ pooled primer mixture, $0.75 \mu \mathrm{L}$ of PCR certified water, and $1.25 \mu \mathrm{L}$ of cDNA per reaction. STA was performed in a thermal cycler (T100, Bio-Rad Laboratories, Munich, Germany) using the following temperature program: $10 \mathrm{~min}$ at $95^{\circ} \mathrm{C}$ followed by 12 cycles of $15 \mathrm{~s}$ at $95^{\circ} \mathrm{C}$ and $4 \mathrm{~min}$ at $60{ }^{\circ} \mathrm{C}$ and a final holding temperature of $4{ }^{\circ} \mathrm{C}$. Afterwards, $0.4 \mu \mathrm{L}$ of exonuclease I (Exo I) (initial activity 20 units $/ \mu \mathrm{L}$ ) was diluted to 4 units $/ \mu \mathrm{L}$ with $0.2 \mu \mathrm{L}$ of $10 \mathrm{X}$ Exonuclease I Reaction Buffer and $1.4 \mu \mathrm{L}$ of PCR certified water per reaction. $2 \mu \mathrm{L}$ of the exonuclease reaction mixture were added to the STA samples and digestion with Exo I at 4 units/ $\mu \mathrm{L}$ was performed according to the following temperature program: $40 \mathrm{~min}$ at $37^{\circ} \mathrm{C}, 15 \mathrm{~min}$ at $80^{\circ} \mathrm{C}$, and a final holding temperature at $4{ }^{\circ} \mathrm{C}$. STA and Exo I-treated samples were diluted fivefold with $18 \mu \mathrm{L}$ of TE buffer. For qPCR, forward and reverse primers (initial concentrations $100 \mu \mathrm{M}$ ) were diluted to $5 \mu \mathrm{M}$ by adding $2.5 \mu \mathrm{L}$ of each primer pair to $25 \mu \mathrm{L}$ of $2 \mathrm{X}$ Assay Loading Reagent and $22.5 \mu \mathrm{L}$ of DNA suspension buffer. For the sample mix, $2.25 \mu \mathrm{L}$ of STA and Exo I-treated samples were mixed with $2.5 \mu \mathrm{L}$ of 2X SsoFast ${ }^{\mathrm{TM}}$ EvaGreen ${ }^{\circledR}$ Supermix with Low ROX and $0.25 \mu \mathrm{L}$ of 20X DNA Binding Dye Sample Loading Reagent. Preparation and loading of Fluidigm 96.96 Dynamic Array IFC (integrated fluidic circuit) was performed according to the manufacturer's instructions. After loading, the chip was transferred into the BioMark ${ }^{\mathrm{TM}}$ System (Fluidigm, San Francisco, USA) and qPCR as well as melting curve analysis were performed by running the following temperature program: $2400 \mathrm{~s}$ at $70{ }^{\circ} \mathrm{C}$ and $30 \mathrm{~s}$ at $60{ }^{\circ} \mathrm{C}$, followed by a hot start for $60 \mathrm{~s}$ at $95^{\circ} \mathrm{C}, 30 \mathrm{PCR}$ cycles of $5 \mathrm{~s}$ at $96{ }^{\circ} \mathrm{C}$ for denaturation and $20 \mathrm{~s}$ at $60{ }^{\circ} \mathrm{C}$ for annealing and elongation. The melting curve analysis consisted of $3 \mathrm{~s}$ at $60{ }^{\circ} \mathrm{C}$ followed by heating up to $95^{\circ} \mathrm{C}$ with a ramp rate of $1{ }^{\circ} \mathrm{C} / 3 \mathrm{~s}$. Data analysis and depiction was accomplished with Fluidigm Real-Time PCR Analysis and with GenEx software. For normalization, five potential reference genes were available (ACTB, B2 M, GAPDH, GUSB, and $H P R T 1)$. Finally, potential alterations of the transcript levels of the target genes under investigation were displayed as fold change compared to a control group by calculating relative quantities corresponding to the $\Delta \Delta C_{\mathrm{q}}$ method (Livak and Schmittgen 2001).

\section{Statistics}

For statistical analyses of the data, differences between control and treated samples were analyzed by one-way analysis of variance (ANOVA) followed by the appropriate post hoc-test. The data were tested for homogeneity of variances via Levene test and two-sided Dunnett's $T$ test was used in case of homogeneity, whereas a two-sided Dunnett's $T 3$ test was applied upon variance inhomogeneity.

\section{Results}

\section{Cytotoxicity}

In a first step, we investigated the cytotoxicity of BPDE in TK6 cells after $1 \mathrm{~h}$ treatment. Up to $100 \mathrm{nM}$ BPDE, no or very slight cytotoxicity was observed, determined as colony forming ability. At $200 \mathrm{nM}$ BPDE, a significant decrease to $50 \%$ of control occurred (Fig. 1). For subsequent experiments, the low, non-cytotoxic dose range up to $50 \mathrm{nM}$ was applied for DNA adduct quantification and mutagenicity testing, while the whole concentration range was applied for gene expression profiling to ensure the detection of effects occurring in the non-cytotoxic range, but also those effects restricted to cytotoxic concentrations.

\section{Induction of DNA adducts by BPDE}

Next, we investigated the induction of DNA adducts by BPDE after $1 \mathrm{~h}$ treatment. We applied a sensitive test system, based on the formation of stable adducts predominantly at the $N^{2}$-position of guanine and the subsequent release of tetrols after acid hydrolysis. The tetrols were very sensitively quantified by HPLC with fluorescence detection, allowing the quantification of as little as 1 adduct $/ 10^{8}$ base pairs or about 60 adducts per cell, requiring 10-100 $\mu$ g DNA (Schwerdtle et al. 2002). 


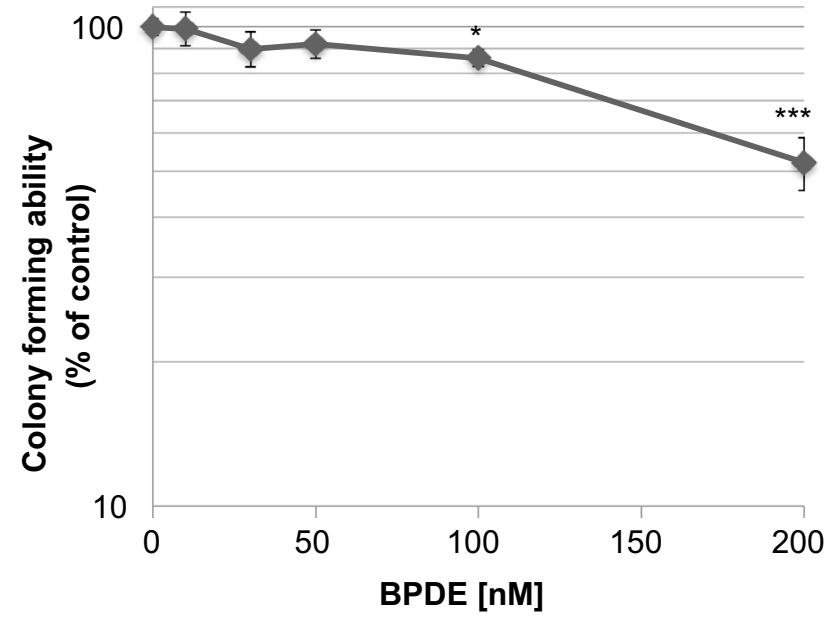

Fig. 1 Cytotoxicity of BPDE determined via colony forming ability after $1 \mathrm{~h}$ treatment in TK6 cells. Shown are mean values of six determinations derived from two independent experiments \pm SD. Statistically significant different from control: $* p \leq 0.05, * * * p \leq 0.001$ (ANOVA-Dunnett's $T$ test)

As shown in Fig. 2, a linear dose-response was observed in low dose range, yielding around 100 lesions $/ 10^{8}$ base pairs at $10 \mathrm{nM}$ and around 500 lesions $/ 10^{8}$ base pairs at $50 \mathrm{nM}$ BPDE.

\section{Induction of mutations by BPDE}

Subsequently, mutations were quantified by determination of GPI-deficient cells in the newly established in vitro PIG-A mutation assay. Within this test system,

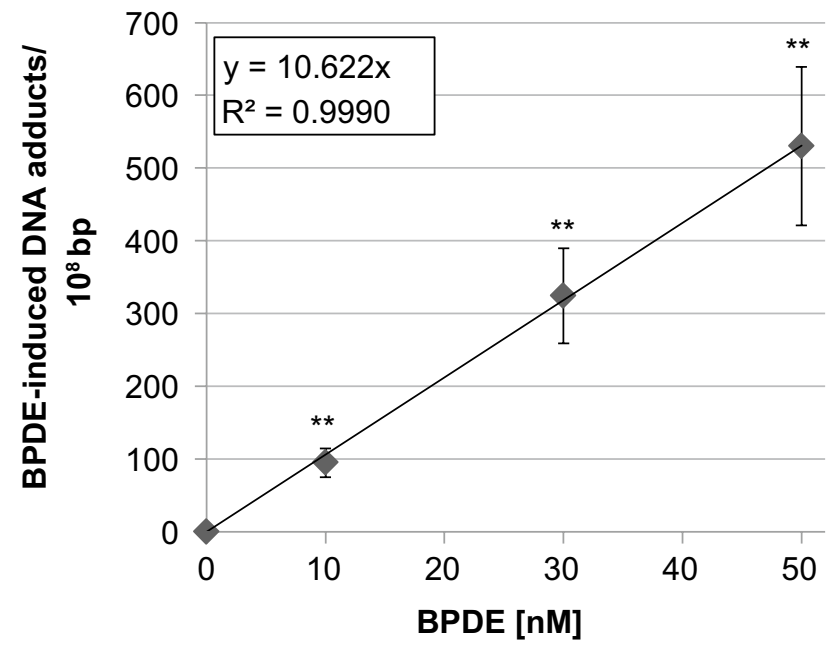

Fig. 2 BPDE-induced DNA adduct levels determined via HPLC/ FD after $1 \mathrm{~h}$ treatment in TK6 cells. Shown are mean values of four determinations derived from two independent experiments \pm SD. Statistically significant different from control: ${ }^{*} p \leq 0.01$ (ANOVADunnett's $T$ test) inactivating mutations in the $P I G-A$ and in the $P I G-L$ gene are phenotypically expressed by the loss of GPIanchored proteins on the cell surface. The mutation frequency is equal to the frequency of GPI-deficient cells, which can be determined by antibody staining of GPIanchored proteins and flow cytometry (Krüger et al. 2015, 2016). As shown in Fig. 3, significantly elevated levels of GPI-deficient cells were observed for the entire concentration range, starting at $10 \mathrm{nM}$ BPDE and resulting in about 180 GPI-deficient cells per $10^{6}$ viable cells at $50 \mathrm{nM}$. Notably, mutations were induced in the completely non-cytotoxic concentration range of BPDE with respect to colony forming ability. As a parameter of cell growth after mutagen treatment, the relative increase in cell count (RICC) was determined, leading to a dosedependent reduction down to about $55 \%$ at $50 \mathrm{nM}$ BPDE (data not shown). All values were well above $10 \%$ as recommended by the OECD to exclude uninformative results in mutagenicity assays. Interestingly, the increase in mutation frequencies was linear with dose, starting at the lowest concentration.

\section{Correlation of DNA adducts and mutations}

As stated in the introduction, one major question addressed in this study was whether or not there is a dose range in which DNA adducts are detectable but do not lead to the induction of mutations yet, perhaps due to efficient repair of DNA lesions in the low dose range. Therefore, mutation frequencies have been plotted against DNA adducts quantified by HPLC. As shown in Fig. 4, there was a linear

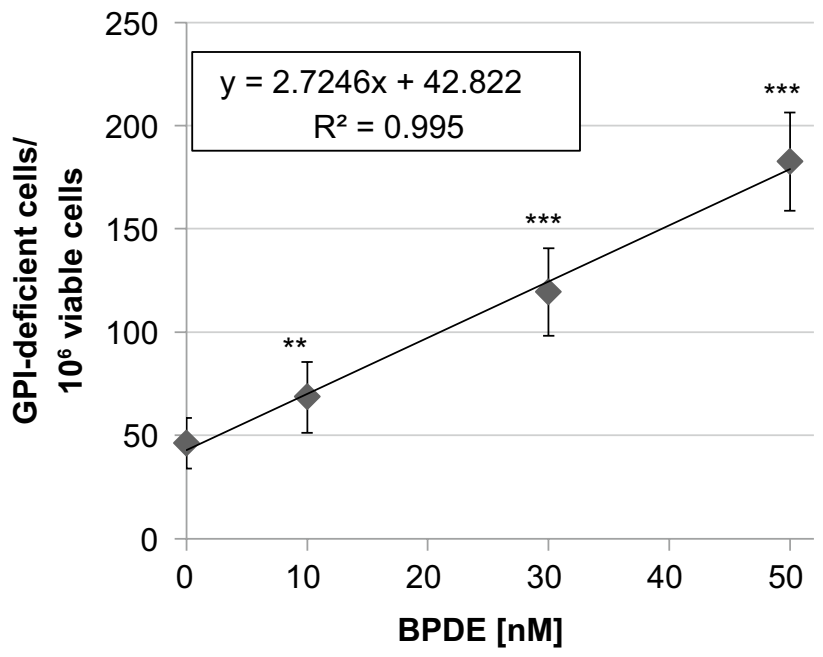

Fig. 3 GPI(-) frequencies of TK6 cells after $1 \mathrm{~h}$ treatment with BPDE and 10 days of phenotype expression. Shown are mean values of 12 determinations derived from two independent experiments \pm SD. Statistically significant different from control: $* * p \leq 0.01, * * * p \leq 0.001$ (ANOVA-Dunnett's $T$ test) 
correlation between the amount of DNA adducts and mutations in the entire concentration range of 0-50 nM BPDE.

\section{Repair of BPDE-induced DNA adducts}

As described above, BPDE-induced DNA adducts are removed via NER. However, actual repair capacities could vary between different cells lines. To exclude that the linear relationship between DNA adducts and mutations is due to missing repair in TK6 cells and to compare repair capacities at different treatment concentrations, we quantified DNA adduct levels after different post-incubation times. As shown in Fig. 5, around 30\% of the adducts were removed within $8 \mathrm{~h}$ after treatment and around $60 \%$ after $24 \mathrm{~h}$. First, this indicates that TK6 cells are repair proficient with respect to NER. Second, interestingly, the relative repair capacity was independent of the BPDE concentration, suggesting that repair efficiency is not increased at lower lesion density in the genome.

\section{Induction of the cellular response to BPDE-induced DNA damage by gene expression profiling}

To elucidate the cellular response to BPDE on the transcriptional level, we applied a recently established highthroughput RT-qPCR analyses with Fluidigm dynamic arrays using the BioMark ${ }^{\mathrm{TM}}$ System (Fischer et al. 2016). This method enables the parallel and quantitative analysis of expression levels of 95 different genes for 96 different samples. Genes were selected according to their relevance for genomic stability, comprising DNA damage response, DNA repair factors, oxidative stress response, cell cycle arrest, cell proliferation and apoptosis, and time- and concentration-dependent analyses were performed. Within the context of this study, one aspect of special interest concerned the question at which level of DNA lesions the DNA damage response would be activated on the transcriptional level. As shown in Fig. 6a, after $1 \mathrm{~h}$ incubation with BPDE and $7 \mathrm{~h}$ post-incubation, DNA damage signaling was evident most pronounced in case of $G A D D 45 A$, followed by RRM2B. Also, the genes coding for the NER repair proteins DDB2 and XPC, both involved in DNA damage recognition, were induced. In each case, the effects were dose-dependent; however, relevant effects reaching twofold activation were restricted to concentrations of $100 \mathrm{nM} \mathrm{BPDE}$ and higher. After $23 \mathrm{~h}$ post-incubation, similar effects were observed; additionally, ATM involved in signaling and repair of DNA double strand breaks, DDIT3 as a further DNA damage inducible gene as well as ERCC4 coding for a NER nuclease were slightly induced (Fig. 6b). Likewise, p53- and AP-1 dependent signaling was observed in a concentrationdependent manner, again with pronounced effects mainly

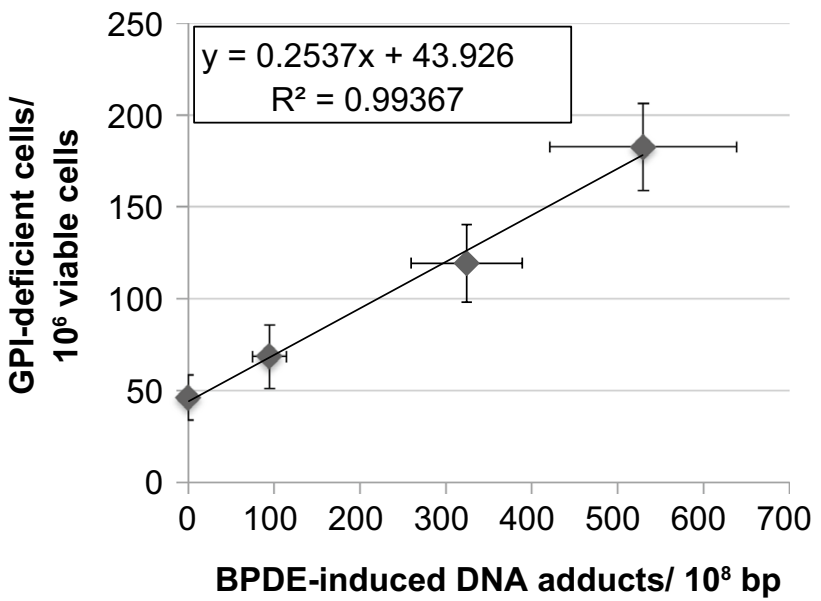

Fig. 4 Correlation between GPI(-) frequencies with BPDE-induced DNA adduct levels in TK6 cells. Shown are mean values of 12 (GPI(-)) or four (DNA adducts) determinations derived from two independent experiments each \pm SD

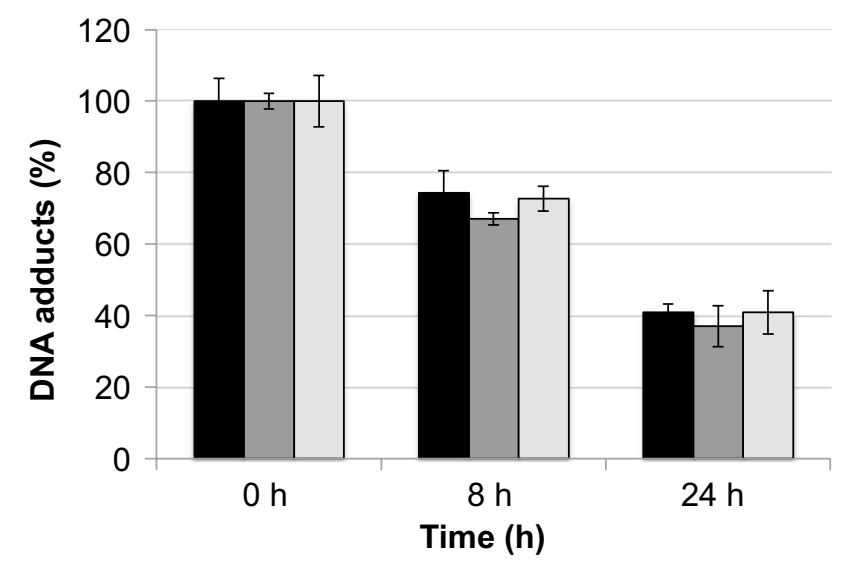

$10 \mathrm{nM}$ BPDE $\quad \square 30 \mathrm{nM}$ BPDE $\quad \square 50 \mathrm{nM}$ BPDE

Fig. 5 Time-dependent repair capacity of BPDE-induced DNA adducts in TK6 cells. For damage induction, cells were treated with the indicated BPDE concentrations for $1 \mathrm{~h}$. Shown are mean values of four determinations derived from two independent experiments \pm SD

restricted to high BPDE concentrations (Fig. 7). Regarding p53-induced target genes, CDKN1A coding for the cell cycle inhibitor p21, the p53 inhibitor MDM2 as well as the p53-inducible phosphatase PPM1D displayed distinct inductions at $100 \mathrm{nM}$ BPDE and higher; in some cases, slight effects occurred already at $50 \mathrm{nM}$. The effects were more pronounced after $23 \mathrm{~h}$ (Fig. $7 \mathrm{~b}$ ) as compared to $7 \mathrm{~h}$ post-incubation (Fig. 7a). The positively auto-regulated JUN expression indicated AP-1 activation, with a relevant enhanced transcription restricted to $200 \mathrm{nM}$ BPDE at both time points. As shown in Fig. 8, a similar doseresponse relationship was evident with respect to the oxidative stress response as well as apoptotic signaling, 


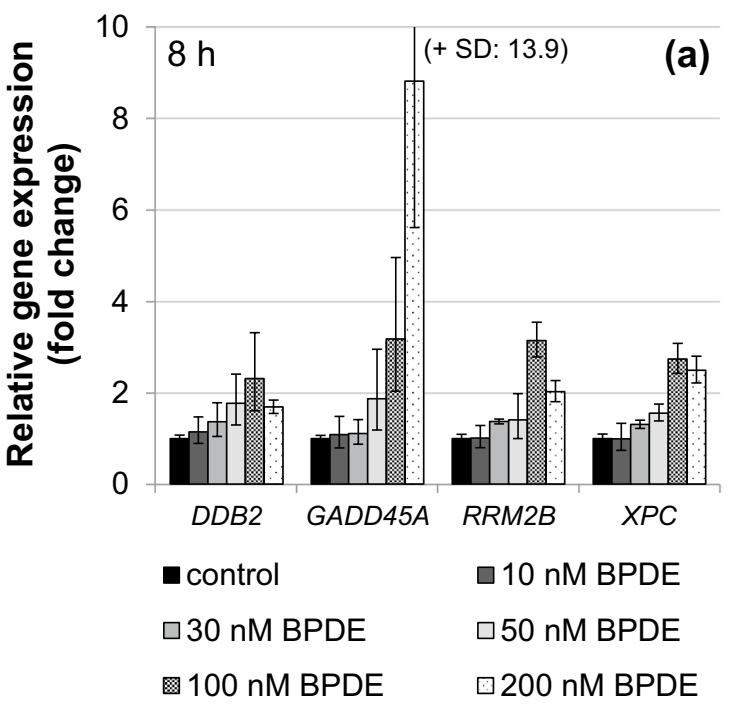

Fig. 6 Impact of BPDE on gene expression related to DNA damage response and repair. TK6 cells were treated with BPDE for $1 \mathrm{~h}$ followed by $7 \mathrm{~h} \mathrm{(a)}$ or $23 \mathrm{~h}$ (b) post-incubation, respectively. Shown

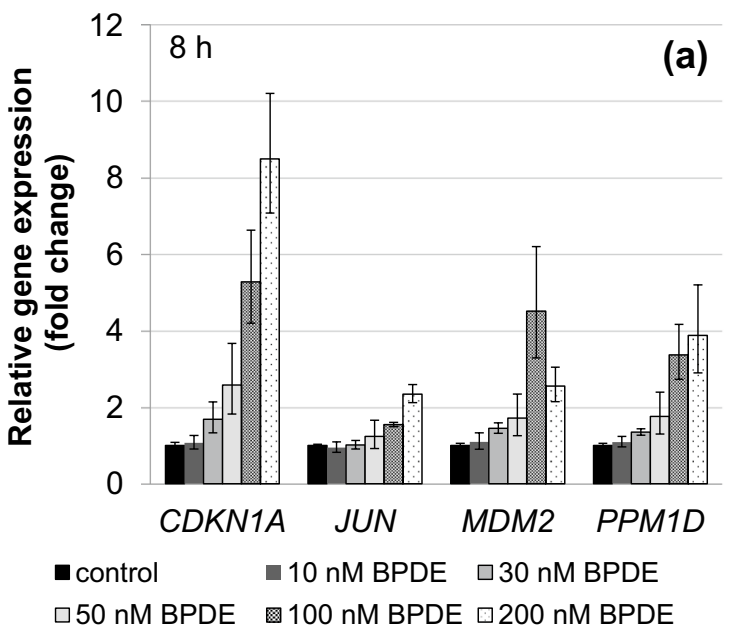

Fig. 7 Impact of BPDE on gene expression related to p53 and AP-1 signaling. TK6 cells were treated with BPDE for $1 \mathrm{~h}$ followed by $7 \mathrm{~h}$ (a) or $23 \mathrm{~h}$ (b) post-incubation, respectively. Shown are linear fold

exerting a clearly pro-apoptotic pattern after $1 \mathrm{~h}$ incubation followed by $23 \mathrm{~h}$ post-incubation. Thus, up to $50 \mathrm{nM}$ BPDE no relevant modulation of gene expression was observed, whereas a more than twofold induction of the pro-apoptotic genes $A P A F 1, B A X$, and $B B C 3$ coding for the p53 up-regulated modulator of apoptosis (Puma), all involved in the intrinsic apoptotic pathway, was evident at $100 \mathrm{nM}$ BPDE and higher. Increased mRNA levels of the pro-apoptotic PMAIP1 coding for Noxa and TNFRSF10B activating the extrinsic apoptotic pathway, as well as the

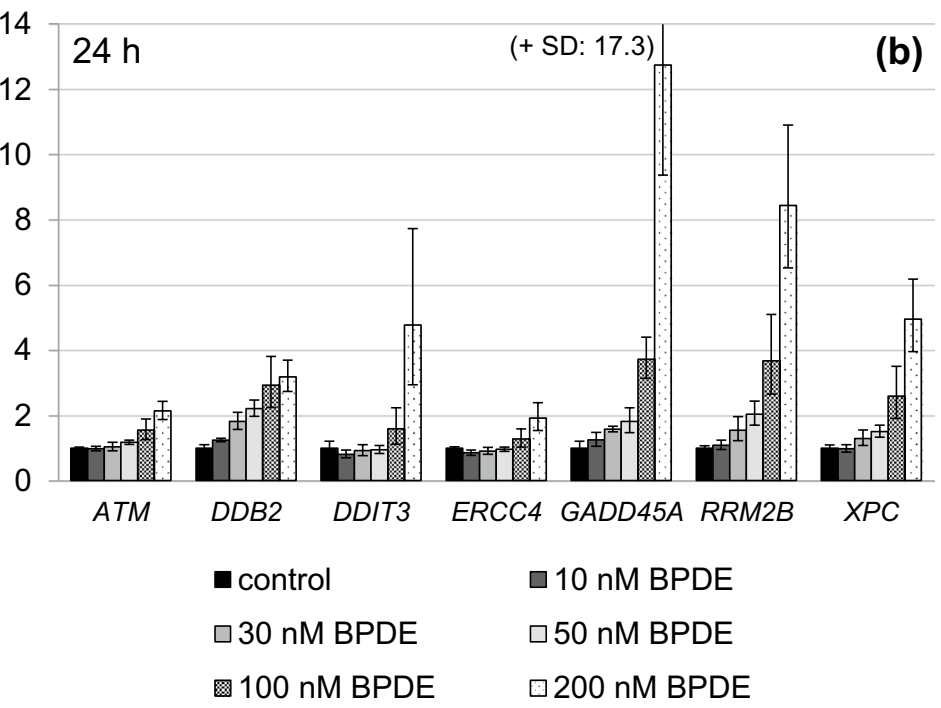

are linear fold changes of the relative gene expression from mean values of four determinations derived from two independent experiments \pm SD

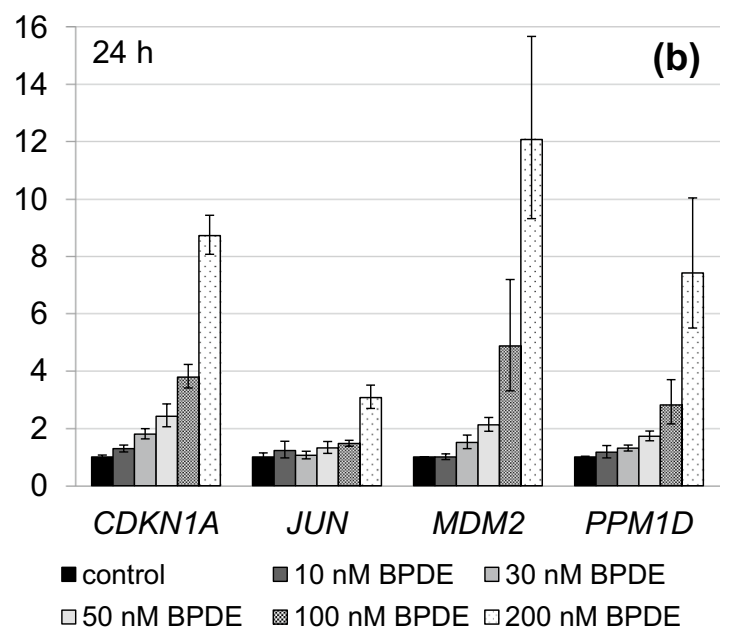

changes of the relative gene expression from mean values of four determinations derived from two independent experiments $\pm \mathrm{SD}$

anti-apoptotic $B C L 2$ were even limited to $200 \mathrm{nM}$ BPDE. Since $B A X, B B C 3, P M A I P 1$, and $B C L 2$ are known $\mathrm{p} 53$ target genes, this tumor suppressor appears to be activated at $100 \mathrm{nM}$ BPDE and higher. Similarly, the transcriptional oxidative stress response as evident by the induction of the ROS-inducible HMOXI together with GPXI and SEPPI as anti-oxidative factors occurred only at the highest concentration of $200 \mathrm{nM}$ BPDE. The complete gene expression profile is provided as a heat map in Supplementary Fig. 1. 
Fig. 8 Impact of BPDE on gene expression related to oxidative stress response and apoptotic signaling. TK6 cells were treated with BPDE for $1 \mathrm{~h}$ followed by $23 \mathrm{~h}$ postincubation. Shown are linear fold changes of the relative gene expression from mean values of four determinations derived from two independent experiments \pm SD

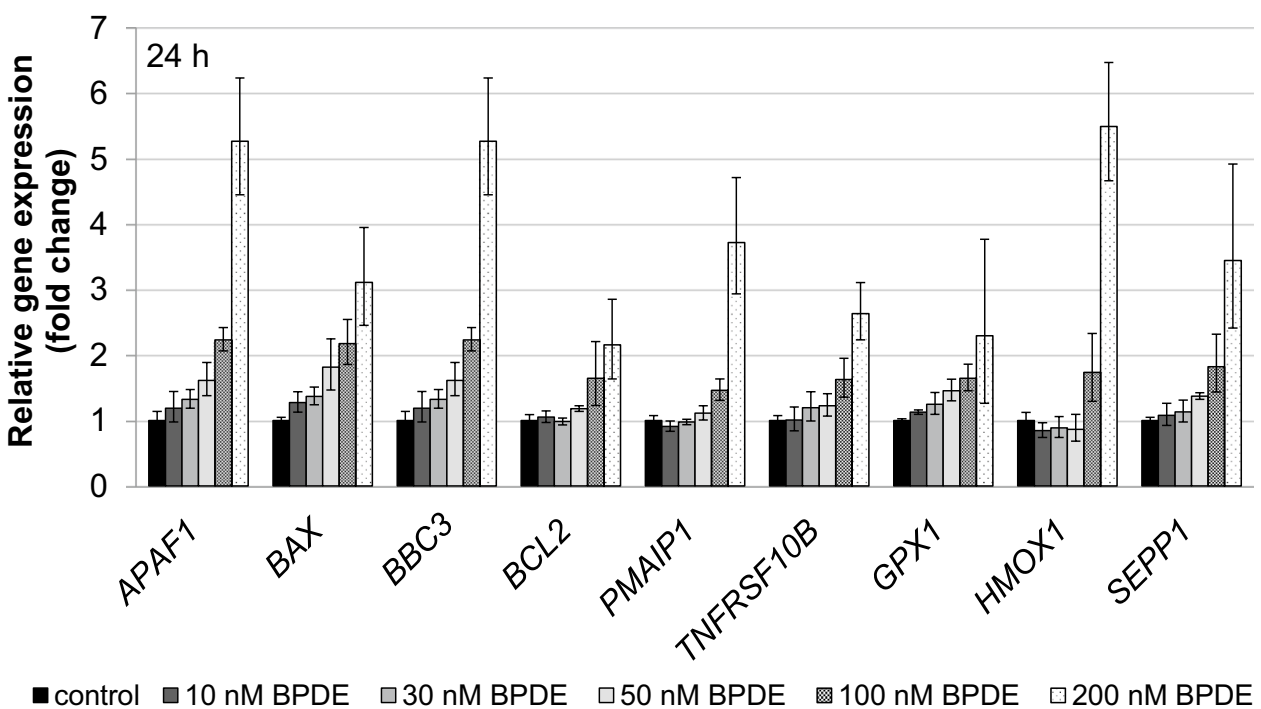

\section{Discussion}

One critical aspect discussed within the context of risk assessment for chemical carcinogens consists in the question whether there is a general "threshold" between the induction of DNA adducts and their conversion into mutations, potentially mediated by efficient repair in case of only few adducts and/or protective adaptive mechanisms within the transcriptional response to DNA damage. This is of particular interest in case of low, for human exposure relevant levels. As stated in the introduction, there have been numerous contributions stating that for alkylating agents there may be a dose range where DNA adducts are measurable but do not result in increased mutation frequencies; for recent review see (Klapacz et al. 2016). Nevertheless, this raises the question whether this is a general phenomenon or restricted to certain DNA lesions.

Within the present study, we selected BPDE, the critical DNA reactive metabolite of $\mathrm{BaP}$, which provokes helix distorting lesions in DNA repaired by NER, to address the question whether there is a concentration range where DNA adducts occur without measurable increase in mutation frequencies. We quantified stable DNA adducts at the $N^{2}$-position of guanine, mutations by the PIG-A assay, as well as the transcriptional response to DNA damage via a high-throughput qRT-PCR technique. Important prerequisites to approach this question were comparable incubation conditions, including the identical cell line, in this case TK6 cells, expressing the GPI anchored proteins used as marker proteins for mutagenicity. Also, with regard to the different endpoints, similar detection sensitivities for the low dose range were of major importance, to exclude that a potential restriction of mutations to higher concentrations results from higher detection limits as compared to DNA adduct levels.

Regarding the quantification of DNA lesions, BPDEDNA adduct levels were measured by a highly sensitive HPLC/fluorescence assay described previously (Schwerdtle et al. 2002). The principle of the procedure consists in the hydrolysis of stable DNA adducts formed at the $N^{2}$ position of guanine by $0.1 \mathrm{~N} \mathrm{HCl}$, yielding the corresponding tetrol I-1 (Rojas et al. 1994). Under our experimental conditions, the assay exerts a detection limit of $1 \mathrm{pg}$ of tetrol $\mathrm{I}-1$, requires $10-100 \mu \mathrm{g}$ DNA and detects 1 adduct $/ 10^{8}$ base pairs or about 60 adducts/cell. This high sensitivity allows the reproducible quantification of adduct formation and repair after incubation with low, non-cytotoxic concentrations of BPDE. Within the present study, significant increases in lesions were detected at concentrations as low as $10 \mathrm{nM}$, with a linear increase up to $50 \mathrm{nM}$ BPDE. For comparison, immunological detection required 25-fold higher concentrations $(0.25 \mu \mathrm{M}$ and above) (Christmann et al. 2016). Regarding the repair of the adducts, only $30 \%$ were removed within $8 \mathrm{~h}$ post-incubation time, and $40 \%$ were still left after $24 \mathrm{~h}$. This repair course is in agreement with previous observations in A549 and HCT116 cells (Grosskopf et al. 2010; Piberger et al. 2014; Schwerdtle et al. 2002), supporting similar repair capacities in different cell lines. Interestingly, repair kinetics were independent of the applied dose, indicating that within this low dose range of BPDE, no differences in relative repair were observed, and thus, no dose showed faster or even complete repair. This may be explained by specific features of NER mediating the repair of stable BPDE-DNA adducts. NER removes structurally unrelated bulky base adducts generating significant helical distortions. According to the current knowledge, it involves at least 30 different proteins and enzymes 
in mammalian cells, including those which are defective in patients suffering from the DNA repair disorder Xeroderma Pigmentosum (XP) complementation groups A through G (de Boer and Hoeijmakers 2000). Two different pathways can be distinguished: the global genome repair (GG-NER) operating in all parts of the genome and the transcriptioncoupled repair (TC-NER) eliminating DNA damage from the transcribed strand of active genes. While TC-NER is usually fast and efficient to restore transcription, GG-NER on the other hand is slower and may be incomplete, leading to an accumulation of mutations in poorly repaired regions (Fousteri and Mullenders 2008; Mullenders et al. 1991). Accordingly, three levels of repair efficiencies have been identified in human fibroblasts after treatment with BPDE: The transcribed strand of the active HPRT gene was repaired about twice as fast as the non-transcribed strand, resulting in 53 and $26 \%$ of adduct removal after $7 \mathrm{~h}$, respectively. In contrast, only $14 \%$ of BPDE adducts were removed from the inactive locus 754 within $20 \mathrm{~h}$ (Chen et al. 1992). In addition, the rates of incision of stereochemically identical BPDE-induced DNA lesions catalyzed by the prokaryotic UvrABC system was shown to be higher in the $\mathrm{TG}^{*} \mathrm{~T}$ than in the $\mathrm{CG}^{*} \mathrm{C}$ sequence context (Ruan et al. 2007), due to differences in structural alterations of the DNA helix (Cai et al. 2007). The longevity of at least some PAH-induced DNA adducts was also shown in lung autopsy samples of non-smokers, ex-smokers, and smokers. Lowest frequencies of lesions were found in the first group, intermediate frequencies in the second, and highest values in the third group. Furthermore, almost all samples even of the non-smoking group had detectable levels of PAH-induced DNA lesions, indicating that even low levels of environmental exposure lead to unrepaired DNA adducts (Lodovici et al. 1998).

In this study, mutations induced by BPDE were quantified by the recently established PIG-A assay. This approach is based on the phenotypic alteration of the GPI status by mutations diminishing the GPI biosynthesis, which can be measured via multicolor flow cytometry with an antibody staining protocol of GPI-anchored proteins CD55 and CD59. In addition to the X-chromosomal $P I G-A$ gene, TK6 cells have been shown to additionally harbour a heterozygous deletion in the $P I G-L$ gene. Since both gene products are required for GPI biosynthesis, there are two reporter genes leading to the same phenotypic alteration, rendering this test system particularly sensitive towards both point mutations and deletions, also when compared to the HPRT assay (Krüger et al. 2015, 2016). Previously, we demonstrated the dose-dependent, statistically significant mutagenicity of ethyl methanesulfonate (EMS), UV-C irradiation, and 4-nitrochinoline- $N$-oxid (NQO), while pyridine and cycloheximide, applied as non-mutagenic negative controls, were also correctly identified as non-mutagens (Krüger et al. 2015). Within the present study, BPDE increased the level of GPI-deficient mutant cells in a dose-dependent manner, with no obvious deviation from linearity also at the lowest concentrations. Furthermore, there was a linear correlation between DNA adduct formation and mutagenicity, again arguing against a "no effect" range in the low dose exposure towards BPDE.

The transcriptional response to $\mathrm{BaP}$ or BPDE-induced DNA damage has been investigated previously, for example via microarray analysis to elucidate the impact of p53 (Hockley et al. 2008). Also, recently, the adaptive up-regulation of selected DNA repair genes was analyzed and correlated to BPDE-induced DNA adduct levels, showing that transcriptional activation protects against BPDE-induced cytotoxicity at the expense of mutations; the latter due to the enhanced expression of error-tolerating POLH (Christmann et al. 2016). Nevertheless, to the best of our knowledge, no gene expression analysis study was conducted in the very low concentration range of 10-200 nM BPDE as it is presented within this study. Furthermore, we applied a high-throughput RT-qPCR technique, enabling quantitative time- and concentration-dependent gene expression analyses for 96 samples in parallel, providing a comprehensive gene expression profile with respect to DNA damage response, DNA repair factors, oxidative stress response, cell cycle arrest, cell proliferation, and apoptosis. Special focus was given to time- and concentration-dependent inductions of gene expression coding for representative factors of the above-mentioned pathways with special relevance for genomic stability, investigated under the same incubation conditions as used for DNA adduct and mutation quantifications. As expected, treatment with BPDE induced genes coding for DNA damage signaling such as GADD45A, DNA repair factors involved in DNA damage recognition during NER, p53 and AP-1 dependent signaling, as well as those coding for oxidative stress response and pro-apoptotic factors. However, almost all significant changes in gene expression were restricted to the two highest concentrations applied, 100 and $200 \mathrm{nM}$ BPDE, while highly significant increases in mutation frequencies were observed at concentration levels 10 - and 20-fold lower. Therefore, neither the induction of DNA repair genes nor, for example, p53-dependent cell cycle control or apoptotic genes were able to protect against BPDE-induced mutations in the very low dose range.

This raises the question how BPDE-induced DNA adducts are converted into mutations. BPDE-induced DNA adducts impair DNA synthesis as well as global replication fork progression, and two mechanisms appear to be associated with overcoming stalled replication fork upon BPDE-induced DNA adducts. One consists in lesion bypass by mainly error-prone DNA translesion synthesis 
(TLS) polymerases. This process is thought to be critical for BaP-caused mutagenicity via the induction of point mutations and has been extensively studied (Bi et al. 2005; Lagerqvist et al. 2011; Temviriyanukul et al. 2012). Additionally, stalled or damaged replication forks may be restarted or repaired via homology-dependent mechanisms (Cohen et al. 2015; Dumstorf et al. 2009; Izhar et al. 2013; Langie et al. 2007). Even though homologous recombination (HR) and HR-dependent mechanisms are intrinsically error-free, recombination could give rise to gross chromosomal instabilities such as genomic rearrangements or loss of heterozygosity when promoted by micro-homology or any other homologous sequence near the fork (Carr and Lambert 2013). Further investigations are needed to clarify whether mutations induced in response to low dose of BPDE as applied in the present study are exclusively mediated via error-prone TLS or might be in part induced by HR events as well.

\section{Conclusions and outlook}

Our study seems to contradict assumptions of a general "biological threshold" for genotoxic carcinogens. Thus, in case of BPDE-induced DNA adducts, both DNA lesion induction, as well as mutagenicity followed linear doseresponse relationships in the very low dose range, and were highly correlated. In contrast, the transcriptional response to DNA damage was restricted to higher, partly cytotoxic concentrations. One reason for the discrepancy between the linear correlation of DNA damage and mutations shown here and the reported "threshold" in response to some alkylating agents appears to be the impact of different types of DNA lesions, especially also different types of DNA repair systems involved in their removal. Without any doubt, NER is a largely error-free process, which protects from mutagenicity, including BPDE-induced DNA adducts (Lagerqvist et al. 2011). Nevertheless, NER may be less effective as compared to BER involved in the removal of different DNA lesions induced by alkylating agents. While the latter repair system removes DNA lesions that also occur endogenously, nucleotide excision repair is involved in the removal of bulky lesions, frequently induced by environmental carcinogens. As described above and shown within the present study, NER has been shown to be slower and less effective, due to heterogeneity of repair throughout the genome and also with respect to the DNA sequence in which the lesion is located. Nevertheless, even though DNA repair capacities were found to be similar in different cells lines, they may differ in vivo in different tissues; this needs to be further investigated. This aspect also accounts for the transcriptional response to DNA damage. Altogether, our results indicate that the question of a "threshold" between the induction of DNA lesions and their conversion into mutations needs to be considered on a case-by-case basis, taking into account different DNA repair systems and respective lesions. Whether or not our observations derived for treatment with BPDE also apply to other substrates of NER requires future research.

Acknowledgements This study was financially supported by the Deutsche Forschungsgemeinschaft (Excellence Initiative KIT) and INST 121384/24-1 FUGG.

\section{Compliance with ethical standards}

Ethical approval This article does not contain any studies with human participants or animals performed by any of the authors.

Conflict of interest The authors declare that they have no competing interests.

Open Access This article is distributed under the terms of the Creative Commons Attribution 4.0 International License (http://creativecommons.org/licenses/by/4.0/), which permits unrestricted use, distribution, and reproduction in any medium, provided you give appropriate credit to the original author(s) and the source, provide a link to the Creative Commons license, and indicate if changes were made.

\section{References}

Bi X, Slater DM, Ohmori H, Vaziri C (2005) DNA polymerase kappa is specifically required for recovery from the benzo $[a]$ pyrenedihydrodiol epoxide (BPDE)-induced S-phase checkpoint. J Biol Chem 280(23):22343-22355. doi:10.1074/jbc.M501562200

Cai Y, Patel DJ, Geacintov NE, Broyde S (2007) Dynamics of a benzo $[a]$ pyrene-derived guanine DNA lesion in TGT and CGC sequence contexts: enhanced mobility in TGT explains conformational heterogeneity, flexible bending, and greater susceptibility to nucleotide excision repair. J Mol Biol 374(2):292-305. doi:10.1016/j.jmb.2007.09.034

Camenisch U, Naegeli H (2009) Role of DNA repair in the protection against genotoxic stress. EXS 99:111-150

Carr AM, Lambert S (2013) Replication stress-induced genome instability: the dark side of replication maintenance by homologous recombination. J Mol Biol 425(23):4733-4744. doi:10.1016/j. jmb.2013.04.023

Chen RH, Maher VM, Brouwer J, van de Putte P, McCormick JJ (1992) Preferential repair and strand-specific repair of benzo[ $a]$ pyrene diol epoxide adducts in the HPRT gene of diploid human fibroblasts. Proc Natl Acad Sci USA 89(12):5413-5417

Christmann M, Boisseau C, Kitzinger R et al (2016) Adaptive upregulation of DNA repair genes following benzo(a)pyrene diol epoxide protects against cell death at the expense of mutations. Nucleic Acids Res 44(22):10727-10743. doi:10.1093/nar/ gkw873

Cohen IS, Bar C, Paz-Elizur T et al (2015) DNA lesion identity drives choice of damage tolerance pathway in murine cell chromosomes. Nucleic Acids Res 43(3):1637-1645. doi:10.1093/nar/ gku1398

de Boer J, Hoeijmakers JH (2000) Nucleotide excision repair and human syndromes. Carcinogenesis 21(3):453-460

Doak SH, Jenkins GJ, Johnson GE, Quick E, Parry EM, Parry JM (2007) Mechanistic influences for mutation induction curves 
after exposure to DNA-reactive carcinogens. Cancer Res 67(8):3904-3911. doi:10.1158/0008-5472.CAN-06-4061

Dumstorf CA, Mukhopadhyay S, Krishnan E, Haribabu B, McGregor WG (2009) REV1 is implicated in the development of carcinogen-induced lung cancer. Mol Cancer Res 7(2):247-254. doi:10.1158/1541-7786.MCR-08-0399

Fischer BM, Neumann D, Piberger AL, Risnes SF, Köberle B, Hartwig A (2016) Use of high-throughput RT-qPCR to assess modulations of gene expression profiles related to genomic stability and interactions by cadmium. Arch Toxicol 90(11):27452761. doi: $10.1007 / \mathrm{s} 00204-015-1621-7$

Fousteri M, Mullenders LH (2008) Transcription-coupled nucleotide excision repair in mammalian cells: molecular mechanisms and biological effects. Cell Res 18(1):73-84. doi:10.1038/cr.2008.6

Gocke E, Müller L (2009) In vivo studies in the mouse to define a threshold for the genotoxicity of EMS and ENU. Mutat Res 678(2):101-107. doi:10.1016/j.mrgentox.2009.04.005

Greim H, Albertini RJ (2014) Cellular response to the genotoxic insult: the question of threshold for genotoxic carcinogens. Toxicol Res 4:36-45

Grosskopf C, Schwerdtle T, Mullenders LH, Hartwig A (2010) Antimony impairs nucleotide excision repair: XPA and XPE as potential molecular targets. Chem Res Toxicol 23(7):1175-1183. doi:10.1021/tx100106x

Hess MT, Gunz D, Luneva N, Geacintov NE, Naegeli H (1997) Base pair conformation-dependent excision of benzo $[a]$ pyrene diol epoxide-guanine adducts by human nucleotide excision repair enzymes. Mol Cell Biol 17(12):7069-7076

Hockley SL, Arlt VM, Jahnke G, Hartwig A, Giddings I, Phillips DH (2008) Identification through microarray gene expression analysis of cellular responses to benzo(a)pyrene and its diol-epoxide that are dependent or independent of p53. Carcinogenesis 29(1):202-210. doi:10.1093/carcin/bgm227

Izhar L, Ziv O, Cohen IS, Geacintov NE, Livneh Z (2013) Genomic assay reveals tolerance of DNA damage by both translesion DNA synthesis and homology-dependent repair in mammalian cells. Proc Natl Acad Sci USA 110(16):E1462-E1469. doi:10.1073/ pnas. 1216894110

Jenkins GJ, Zair Z, Johnson GE, Doak SH (2010) Genotoxic thresholds, DNA repair, and susceptibility in human populations. Toxicology 278(3):305-310. doi:10.1016/j.tox.2009.11.016

Klapacz J, Pottenger LH, Engelward BP et al (2016) Contributions of DNA repair and damage response pathways to the non-linear genotoxic responses of alkylating agents. Mutat Res Rev Mutat Res 767:77-91. doi:10.1016/j.mrrev.2015.11.001

Krüger CT, Hofmann M, Hartwig A (2015) The in vitro PIG-A gene mutation assay: mutagenicity testing via flow cytometry based on the glycosylphosphatidylinositol (GPI) status of TK6 cells. Arch Toxicol 89(12):2429-2443. doi:10.1007/s00204-014-1413-5

Krüger CT, Fischer BM, Armant O, Morath V, Strahle U, Hartwig A (2016) The in vitro PIG-A gene mutation assay: glycosylphosphatidylinositol (GPI)-related genotype-to-phenotype relationship in TK6 cells. Arch Toxicol 90(7):1729-1736. doi:10.1007/ s00204-016-1707-x
Lagerqvist A, Hakansson D, Lundin C et al (2011) DNA repair and replication influence the number of mutations per adduct of polycyclic aromatic hydrocarbons in mammalian cells. DNA Repair (Amst) 10(8):877-886. doi:10.1016/j.dnarep.2011.06.002

Langie SA, Knaapen AM, Ramaekers CH et al (2007) Formation of lysine 63-linked poly-ubiquitin chains protects human lung cells against benzo[ $a]$ pyrene-diol-epoxide-induced mutagenicity. DNA Repair (Amst) 6(6):852-862. doi:10.1016/j. dnarep.2007.02.012

Livak KJ, Schmittgen TD (2001) Analysis of relative gene expression data using real-time quantitative PCR and the 2(-Delta Delta C(T)) method. Methods 25(4):402-408. doi:10.1006/ meth.2001.1262

Lodovici M, Akpan V, Giovannini L, Migliani F, Dolara P (1998) Benzo $[a]$ pyrene diol-epoxide DNA adducts and levels of polycyclic aromatic hydrocarbons in autoptic samples from human lungs. Chem Biol Interact 116(3):199-212

Melendez-Colon VJ, Luch A, Seidel A, Baird WM (1999) Cancer initiation by polycyclic aromatic hydrocarbons results from formation of stable DNA adducts rather than apurinic sites. Carcinogenesis 20(10): 1885-1891

Mullenders LH, Vrieling H, Venema J, van Zeeland AA (1991) Hierarchies of DNA repair in mammalian cells: biological consequences. Mutat Res 250(1-2):223-228

Piberger AL, Köberle B, Hartwig A (2014) The broccoli-born isothiocyanate sulforaphane impairs nucleotide excision repair: XPA as one potential target. Arch Toxicol 88(3):647-658. doi:10.1007/ s00204-013-1178-2

Pottenger LH, Schisler MR, Zhang F et al (2009) Dose-response and operational thresholds/NOAELs for in vitro mutagenic effects from DNA-reactive mutagens, MMS and MNU. Mutat Res 678(2):138-147. doi:10.1016/j.mrgentox.2009.07.002

Rojas M, Alexandrov K, van Schooten FJ, Hillebrand M, Kriek E, Bartsch H (1994) Validation of a new fluorometric assay for benzo $[a]$ pyrene diolepoxide-DNA adducts in human white blood cells: comparisons with 32P-postlabeling and ELISA. Carcinogenesis 15(3):557-560

Ruan Q, Liu T, Kolbanovskiy A et al (2007) Sequence context- and temperature-dependent nucleotide excision repair of a benzo $[a]$ pyrene diol epoxide-guanine DNA adduct catalyzed by thermophilic UvrABC proteins. Biochemistry 46(23):7006-7015. doi:10.1021/bi700294k

Schwerdtle T, Seidel A, Hartwig A (2002) Effect of soluble and particulate nickel compounds on the formation and repair of stable benzo[ $a]$ pyrene DNA adducts in human lung cells. Carcinogenesis 23(1):47-53

Temviriyanukul P, Meijers M, van Hees-Stuivenberg S et al (2012) Different sets of translesion synthesis DNA polymerases protect from genome instability induced by distinct food-derived genotoxins. Toxicol Sci 127(1):130-138. doi:10.1093/toxsci/kfs074

Verma N, Pink M, Rettenmeier AW, Schmitz-Spanke S (2012) Review on proteomic analyses of benzo[ $[a]$ pyrene toxicity. Proteomics 12(11):1731-1755. doi:10.1002/pmic.201100466 